\title{
Estimating Nursing Wage Bill in Canada and Breaking Down the Growth Rate: 2000 to 2010
}

\section{Estimation de la masse salariale de la main-d'œuvre infirmière au Canada et ventilation du taux de croissance : de 2000 à 2010}

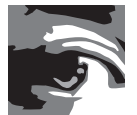 \\ RUOLZ ARISTE, MSC \\ $\mathrm{PhD}$ Candidate, Joint Industrial Relations Program \\ Université du Québec en Outaouais \\ Department of Industrial Relations, Université Laval \\ Gatineau, QC \\ ALI BÉJAOUI, PHD \\ Associate Professor, Department of Industrial Relations \\ Université du Québec en Outaouais \\ Gatineau, QC
}

\begin{abstract}
Even though the nursing professional category (registered nurses [RNs] and licensed practical nurses) made up about one-third of the Canadian health professionals, no study exists about their wage bill, the composition and growth rate of this wage bill. This paper attempts to fill this gap by estimating the nursing wage bill in the Canadian provinces and breaking down the growth rate for the 2000-2010 period, using the 2001 Census and the 2011 National Household Survey. Total wage bill for the nursing professional category in Canada was estimated at $\$ 20.1$ billion ( $\$ 17.3$ billion for $\mathrm{RNs}$ ), which suggests that it is as substantial as net physician remuneration. The average annual growth rate of this wage bill was $6.6 \%$ for RNs. This increase was mainly driven by real (inflation-adjusted) wage per hour, which was $3.0 \%$, suggesting the existence of a "health premium" of 1.7 percentage points during the study period.
\end{abstract}




\section{Résumé}

Bien que la catégorie des infirmières professionnelles (infirmières autorisées et infirmières auxiliaires autorisées) représente près du tiers des professionnels de la santé au Canada, il n'existe aucune étude sur la masse salariale de ce groupe, ni sur la composition ou le taux de croissance de cette masse salariale. Cet article tente de combler cette lacune en estimant la masse salariale de la main-d'œuvre infirmière selon les provinces du Canada et en ventilant le taux de croissance pour la période entre 2000 et 2010 au moyen du Recensement de 2001 et de l'Enquête nationale auprès des ménages de 2011. Le total de la masse salariale de la main-d'œuvre infirmière au Canada était estimé à 20,1 milliards de dollars (17,3 milliards pour les infirmières autorisées), ce qui laisse entendre qu'elle est aussi importante que la rémunération nette des médecins. Le taux de croissance annuel de cette masse salariale était de 6,6 \% pour les infirmières autorisées. Cette croissance était principalement motivée par le salaire horaire réel (corrigé selon l'inflation), qui était de 3,0 \%, ce qui suggère l'existence d'une "prime de santé » de l'ordre de 1,7 points de pourcentage au cours de la période de l'étude.

\section{Introduction}

During the past 10 years, healthcare spending growth has gained increasing attention by policy makers in Canada and other industrialized countries because of its rising trends (CIHI 2010; Hartwig and Sturm 2014). Given that health is a labour-intensive sector, compensation is expected to be an important component of this trend. While physician compensation has been extensively studied (Ariste forthcoming; Barer and Evans 1983; CIHI 2006, 2010, 2014; Contandriopoulos and Perroux 2013), it is not the case for nurses, in spite of the fact that they made up about one-third of the Canadian health professionals. In fact, nurses are an important entity in the Canadian healthcare system. They include essentially registered nurses (RNs, including registered psychiatric nurses in the four Western provinces) and licensed practical nurses (LPNs - the applicable term in Ontario is RPNs: registered practical nurses) ${ }^{1}$ and were 354,910 in 2010 in Canada (CIHI 2011). They typically work in hospitals, longterm care facilities and clinics and are paid mainly from public funds. Numerous studies have been done on the number of nurses, their characteristics, employment status, hours worked as well as on retention factors (Baumann et al. 2010; O’Brien-Pallas et al. 2004; Zeytinoglu et al. 2006). Also, some studies on nurses' wages exist (Buhr 2006; Vujicic 2003). However, to our knowledge, there is no study that looks at the level of, trend in and decomposition of wage bills for nurses in Canada. The present paper uses the Census and the National Household Survey (NHS) from Statistics Canada to address this gap in the literature. Therefore, the objective of this study is to estimate the nursing wage bill in 2010, to examine the trends during the 2000-2010 period and to better understand the different components of this wage bill growth.

Being able to distinguish between the effects of unit cost (wage per hour) and magnitude of volume on nursing wage bill can help policy makers and health system administrators to 
better understand the costs of providing healthcare in Canada. In fact, the policy implication of a growing wage bill is different depending on which component of the bill is growing. If the wage per hour is the main cost driver, this means that we are paying more, but not necessarily getting more nursing throughput (more nurses and/or more worked hours). On the other hand, if the volume or throughput is the main driver, this might not be a bad thing because we are potentially getting more services. The following key questions are addressed:

+ What is the total wage bill for RNs and LPNs in Canada in 2010?

- What is the growth rate of this wage bill during the past decade and which component was mainly responsible for this growth rate?

This study estimates growth in average hourly wage per hour for nurses and compares it with that in the quantity of nurse labour (number of nurses and average number of hours worked) on one hand. On the other hand, growth in average hourly wage per hour for nurses is also compared with that in average hourly wage per hour for other workers. This allows us to assess whether (1) wage per hour was the main cost driver of the nursing wage bill and (2) the nursing sector has benefited from a wage premium compared to the other sectors of the economy. These policy issues are not studied in the Canadian literature. Hence, this paper attempts to fill this gap. The rest of the paper is organized as follows: The second section presents the data and methodology. The results are presented and interpreted in the third section, followed by the conclusion in the fourth section.

\section{Data and Methodology}

Data sources include the 2001 Census and the 2011 NHS from Statistics Canada (2003, 2011, 2013). The Census included a short- and a long-form questionnaire, both mandatory before 2011. However, the long-form questionnaire has been made optional, via the 2011 NHS. The Census and NHS data contain detailed information on average annual income of personnel from different professional categories, including nurses.

Moreover, the regulated nursing occupational category has not changed between the 2001 and 2011 surveys. It refers to three nursing groups: head nurses and supervisors (D111), RNs (D112) and LPNs (D233). ${ }^{2}$ Besides, NHS survey respondents were also given the choice to give Statistics Canada permission to use income information available in their income tax files instead of answering the multiple-part income question. Almost three-quarters (73.2\%) of respondents to the NHS gave permission to use income information available on their income tax files. The item response rate for total wages and salaries after retrieval of tax data was 59.2\% in the 2011 NHS, compared to $79.3 \%$ in the 2006 Census (Statistics Canada 2011). The average annual income was finally determined based on both self-reported ${ }^{3}$ and linked tax data. ${ }^{4}$

In spite of the fact that response rate for income was generally lower in the NHS compared to the Census, the quality of the income estimates in the 2011 NHS is deemed at least 
as substantial as the 2001 Census, where response rate was higher but permission to use the income information available in income tax files was not asked. Consequently, all the 2001 income data were self-reported. Overall, income estimates for the nursing occupational category from the 2011 NHS remain comparable to those of the 2001 Census.

Total nursing wage bill can be defined as average income per nurse times the number of nurses:

$$
\text { Tot Wage Bill }=\frac{\text { Income }}{\text { Nurse }} * \text { Nbr of Nurses }
$$

From a public policy perspective, it is more insightful to further break down total annual wage bill, as we can more fully understand the factors influencing changes in the estimated spending on nurses. Average annual income per nurse can be decomposed into wage per hour and number of hours worked in one year:

$$
\text { Tot Wage Bill }=\frac{\text { Wage }}{\mathrm{Hr}} * \text { Nbr of Hours } * 52 * \text { Nbr of Nurses }
$$

The term "Nbr of Hours" refers to average weekly hours worked per nurse. Actual hours were used. ${ }^{5}$ Both full-time and part-time nurses were included. Hourly and/or weekly wages are calculated together with the working hours per week.

Equation (2) can be further divided to also take into account the population:

$$
\text { Tot Wage Bill }=\frac{\text { Wage }}{\mathrm{Hr}} * \text { Nbr of Hours } * 52 * \frac{\text { Nbr of Nurses }}{\text { Pop }} * \text { Pop }
$$

Total wage bill is expressed as the product of wage per hour times the number of hours worked per year per nurse times the number of nurses per habitant times the number of habitants. Using the natural logarithms of the terms in equation (3) permits to approximate the annual rate of change in total wage bill as the sum of the annual rates of change in wage per hour, number of hours worked and number of nurses per thousand and population. Note that this nominal (without adjusting for inflation) annual rate of change in wage per hour has been further decomposed into change in general inflation and change in real (after adjusting for inflation) wage per hour. The general inflation rate was calculated using the Consumer Price Index. This adds a fifth component in the breakdown of the total wage bill, which gives a framework relatively similar to the one used in the Canadian Institute for Health Information (CIHI 2010) healthcare cost driver study, except for the population aging factor, which is not included in the framework of this study. ${ }^{6}$

Total compensation is estimated by the product of the average annual employment income and the total number of workers in each of the three nursing groups. The overall total compensation is the sum of the three nursing groups. A weighted average hourly wage is also estimated for these groups. Then, total compensation growth is broken down into general inflation, population growth and growth in wage per hour above and beyond general inflation, 
in number of weekly hours worked and in number of nurses per thousand. The first two components (general inflation and population growth) are macroeconomic factors not amenable to policy change within the health sector. Note that the quantity of services, which is a key factor in assessing cost drivers, is not explicitly measured in this paper. It is proxied by the quantity of labour (number of nurses per thousand population and average number of weekly hours), by implicitly assuming that more throughput turns into more services. Finally, it should be noted that the data elements from the NHS and the Census were obtained via a custom-run request to Statistics Canada, and not directly via the public-use microfile of these surveys.

For triangulation purposes, the administrative Nursing Database (NDB) from the CIHI has been used for the count of nurses. Besides, the Labour Force Survey (LFS) from Statistics Canada and the Canadian Federation of Nurses Union document (CFNU 2011a) have been used to compare average hourly wage of nursing professionals. Also, the Survey of Employment, Payroll and Hours (SEPH), an administrative and industry-based data source from Statistics Canada, has been used to compare average hourly wage of all workers. Wherever possible, estimated total wage bill was compared to figures from provincial health ministries.

\section{Results}

\section{Level of wage bill}

In 2010, the total wage bill in Canada was estimated at $\$ 20.1$ billion for all regulated nurses, $\$ 17.3$ billion for front-line RNs and $\$ 2.2$ billion for LPNs (Table 1). The difference ( $\$ 0.6$ billion) represents the wage bill for head nurses and supervisors. Spending (wage bill) for regulated nurses in Canada represents about $73 \%$ of total physician spending. In fact, the latter was estimated at $\$ 27.4$ billion in 2010 (CIHI 2013). This includes overhead costs (administrative charges, nurse salaries, rent, etc.), which can represent from 24 to $31 \%$ of gross physician remuneration (CMA 2010). This suggests that the wage bill for regulated nurses is as important as net physician remuneration and is not trivial. ${ }^{7}$ Not surprisingly, the two most populous provinces (Ontario and Quebec) were responsible for more than half (56\%) of the total wage bill for nurses in Canada. 
Estimating Nursing Wage Bill in Canada and Breaking Down the Growth Rate: 2000 to 2010

TABLE 1. Estimated total wage bill for nurses, wage per hour, number of weekly hours worked and number of nurses per thousand, 2010

\begin{tabular}{|c|c|c|c|c|c|c|c|c|c|}
\hline & \multicolumn{3}{|c|}{$\begin{array}{l}\text { Total wage bill } \\
\text { ( } \$ \text { million) }\end{array}$} & \multicolumn{2}{|c|}{$\begin{array}{l}\text { Wage per hour } \\
\text { (\$) }\end{array}$} & \multicolumn{2}{|c|}{$\begin{array}{l}\text { Number of weekly } \\
\text { hours worked }\end{array}$} & \multicolumn{2}{|c|}{$\begin{array}{l}\text { Number of nurses } \\
\text { per thousand }\end{array}$} \\
\hline & $\begin{array}{l}\text { All } \\
\text { nurses }\end{array}$ & RN* & LPN & $\mathbf{R} \mathbf{N}^{*}$ & LPN & $\mathbf{R} \mathbf{N}^{*}$ & LPN & $\mathbf{R} \mathbf{N}^{*}$ & LPN \\
\hline NL & 447.0 & 363.4 & 79.2 & 35.8 & 23.1 & 32.9 & 35.4 & 11.4 & 3.6 \\
\hline PEI & 104.4 & 90.2 & N/A & 31.2 & $N / A$ & 31.9 & $N / A$ & 12.3 & N/A \\
\hline NS & 652.0 & 545.2 & 88.9 & 32.3 & 20.9 & 34.0 & 34.3 & 10.1 & 2.5 \\
\hline NB & 555.2 & 468.5 & 78.0 & 33.0 & 20.6 & 33.8 & 32.9 & 10.7 & 2.9 \\
\hline $\mathrm{QC}$ & $4,075.2$ & $3,278.2$ & 565.8 & 32.1 & 21.5 & 30.8 & 30.6 & 8.1 & 2.1 \\
\hline ON & $7,319.5$ & $6,455.7$ & 635.8 & 35.1 & 23.8 & 34.0 & 33.3 & 7.9 & 1.2 \\
\hline$M B$ & 867.4 & 770.0 & 80.8 & 35.5 & 23.7 & 32.4 & 31.7 & 10.5 & 1.7 \\
\hline SK & 852.7 & 756.1 & 79.4 & 38.9 & 23.8 & 33.2 & 33.8 & 10.7 & 1.8 \\
\hline$A B$ & $2,552.3$ & $2,231.1$ & 270.2 & 39.0 & 25.0 & 31.6 & 32.7 & 9.3 & 1.7 \\
\hline$B C$ & $2,600.7$ & $2,263.9$ & 260.4 & 35.3 & 24.3 & 32.2 & 32.0 & 8.6 & 1.4 \\
\hline Canada & $20,104.1$ & 17,289.3 & $2,158.1$ & 35.0 & 23.1 & 32.6 & 32.4 & 8.6 & 1.6 \\
\hline
\end{tabular}

*Front-line registered nurses.

$\mathrm{N} / \mathrm{A}=$ not available (data for LPN in PEI are not available due to sample size issue).

Average wage per hour in 2010 in Canada was estimated at $\$ 35.0$ for RNs and $\$ 23.1$ for LPNs. RN wage per hour was higher in Alberta and Saskatchewan and lower in PEI and Quebec. Average number of hours worked per week in 2010 in Canada was virtually the same for RNs and LPNs, 32.6 and 32.4, respectively. The pattern is basically similar in the provinces, except in Newfoundland-Labrador, where LPNs tend to work a bit more hours than RNs. There is not much variability in the number of hours worked among provinces, even though Quebec RNs tend to work a bit fewer hours (30.8 compared to the high of 34.0 in Ontario). Finally, the number of front-line RNs per thousand population was 8.6 at the Canada level, with a high of 12.3 in PEI and a low of 7.9 in Ontario. LPNs at the national level averaged 1.6 per thousand population, with a high of 3.6 in Newfoundland-Labrador and a low of 1.2 in Ontario.

\section{Average Annual Growth in Total Wage Bill and Decomposition}

This section of the paper focuses on growth in the nursing wage bill for the period 20002010. Figure 1 presents the average annual growth and breaking down of the total wage bill for regulated nurses, by jurisdiction. 
FIGURE 1. Average annual growth in the total wage bill of regulated nurses and decomposition, by jurisdiction: 2000-2010

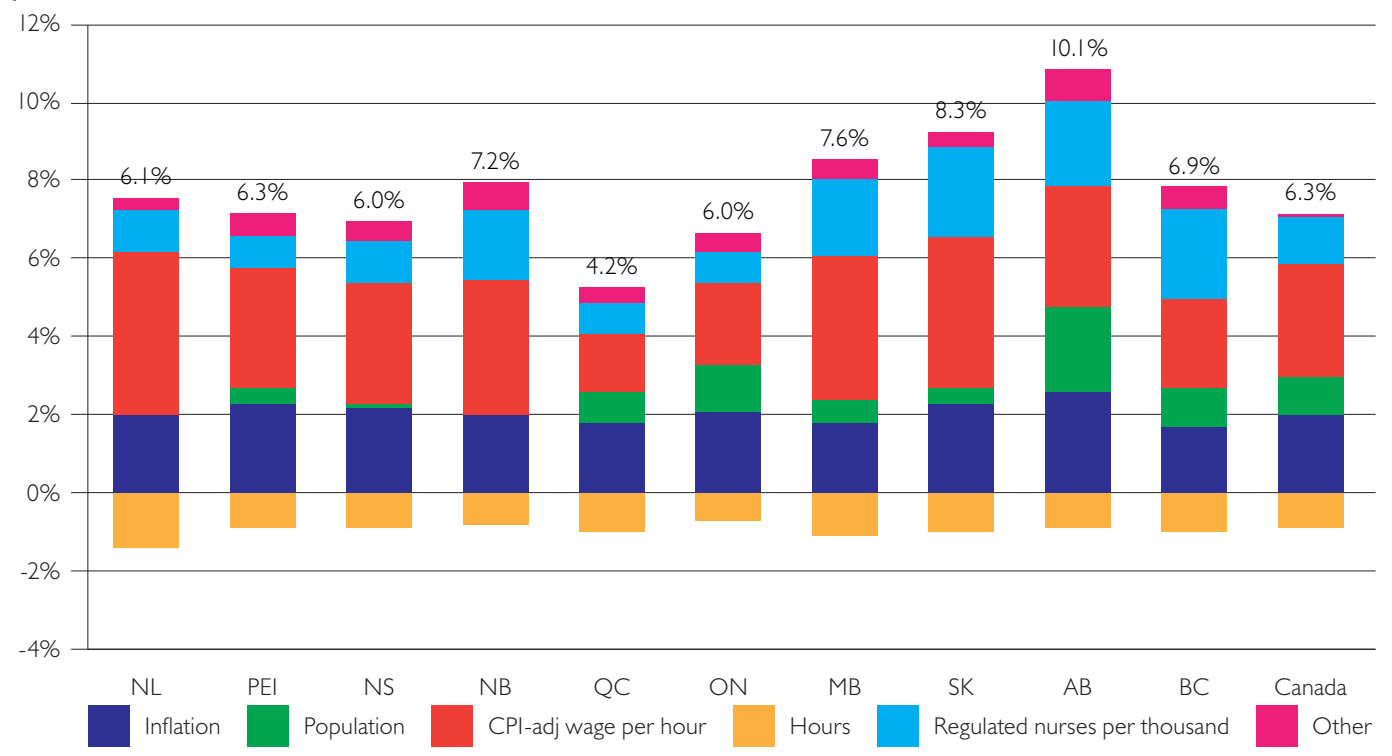

Total wage bill for regulated nurses (the nursing professional category as a whole) in Canada was estimated at $\$ 10.9$ billion in 2000 . Since then, it grew at an average annual rate of $6.3 \%$ to reach $\$ 20.1$ billion in 2010 . Among the provinces, the average annual growth rate varied from a high of $10.1 \%$ (Alberta) to a low of $4.2 \%$ (Quebec). The key policy question is what were the cost drivers of the total nursing wage bill in each jurisdiction? Decomposition of this nursing wage bill helps address this question. After removing general inflation and population growth, which, at the Canada level, were $2.0 \%$ and $1.0 \%$, respectively, the adjusted wage bill for regulated nurses still grew at 3.3\% at the Canada level. This growth was mainly driven by real wage per hour (hourly wage growth above and beyond general inflation), which rose at an average annual rate of $2.9 \%$. Growth in the number of regulated nurses per thousand $(1.2 \%)$ contributed also to the growth in the total wage bill. However, this was partially offset by growth in average number of weekly hours worked, which was rather negative $(-0.9 \%)$, suggesting that professionals in the nursing category worked less time in 2010 than in 2000. The same trend was observed in the general economy, even though to a lesser extent $(-0.3 \%)$. It seems to be a paradox given the perceived shortage of nurses in Canada during this period and evidence of nurse overtime and overwork (O'Brien-Pallas et al. 2004), as well as the higher percentage of RNs employed full-time - 52.0\% in 2000 versus $58.0 \%$ in $2010 .{ }^{8}$ Absenteeism could be perceived as being partly responsible for the decline in worked hours. In fact, $9 \%$ of public-sector full-time healthcare nurses were absent each week in 2010 owing to own illness or disability, nearly twice the rate of all other occupations (CFNU 2011b). However, it should be noted that this rate of absenteeism had not changed much during the 2000s, ${ }^{9}$ which suggests looking for reasons elsewhere. Seemingly, the aging of the nursing workforce could be partly responsible for the increase in real wage per hour. As a matter 
of fact, the percentage of RNs aged 50 and over in the workforce grew from $29.0 \%$ in 2000 to $40.3 \%$ in 2010 (CIHI 2011) ${ }^{10}$ Assuming that age is correlated with tenure, more senior nurses mean higher hourly costs. It also means more vacation time. So, the aging factor could be partly responsible for both the increase in hourly rate and the decrease in weekly hours worked. There could be other potential explanations. ${ }^{11}$ At the provincial level, the pattern is similar. Real wage growth was also the main driver of the increase in nurse wage bill (high of $4.2 \%$ in Newfoundland-Labrador to low of $1.5 \%$ in Quebec), followed by growth in number of nurses per thousand (led by the Western provinces with growth of $2.0 \%$ and higher). Number of weekly hours worked also dropped in each province; the range was narrow around the Canada average ( $-1.3 \%$ in Newfoundland-Labrador to $-0.7 \%$ in Ontario). The component "Other" is a residual that may capture factors such as changes in nursing workload (patient severity) and policy interventions. It is worth investigating how this decomposition looks like for the specific cases of RNs and LPNs. Figure 2 depicts the situation for RNs. Given that general inflation and population growth are macroeconomic factors that do not change with the professional category, they are not reproduced in the figures thereafter.

FIGURE 2. Average annual growth in real wage per hour (\$2002), number of hours worked and number of RN per thousand, by jurisdiction, RN: 2000-20I0

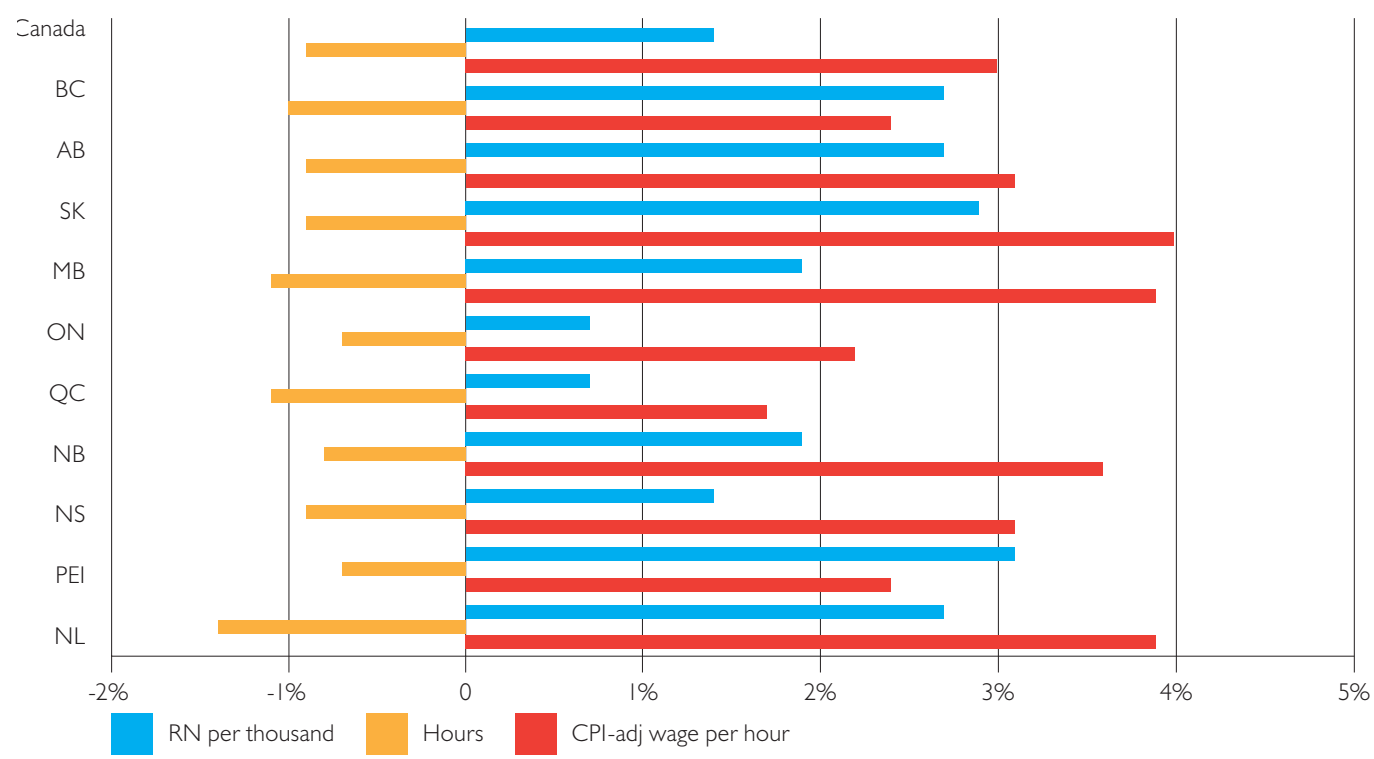

At the Canada level, inflation and population-adjusted wage bill for RNs grew at 3.6\%. Once again, this growth was mainly driven by real wage per hour, which rose at an average annual rate close to $3.0 \%$. Growth in the number of RNs per thousand (1.4\%) contributed also to the growth in wage bill, while growth in average number of hours worked per week was rather negative (-0.9\%), suggesting that RNs worked less time in 2010 than in 2000. It is not surprising that at the Canada level, the findings for RNs are similar to those for the nursing category as a whole, given that RNs represent the vast majority of this category (more than 
80\%). At the provincial level, the pattern is similar: real wage per hour was the main factor driving $R N$ wage bill in each province, except in PEI and BC, where number of RN per thousand was the main factor. As previously noted, the policy implication of a growing wage bill is different depending on which component of the bill is growing (see the Introduction). This suggests that, except for PEI and BC, the other provinces are paying more without getting significantly more RN throughput. As for the LPN wage bill, the situation is presented in Figure 3.

FIGURE 3. Average annual growth in real wage per hour (\$2002), number of hours worked and number of LPN per thousand: by jurisdiction: LPN: 2000-2010

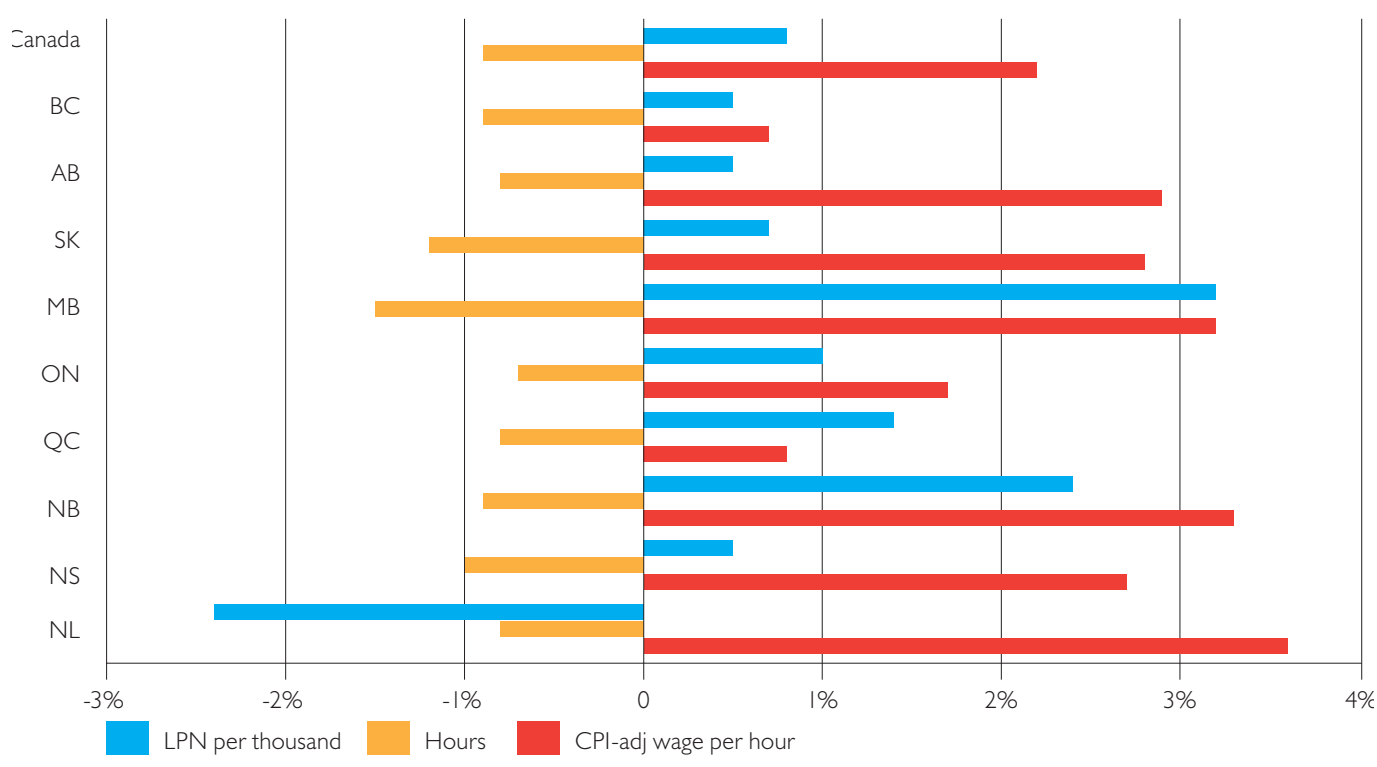

At the Canada level, total wage bill for LPNs grew at an average annual rate of 5.2\%, which is 1.4 percentage points less than RNs. After taking into account general inflation and population growth, the $2.2 \%$ increase in LPN wage bill was totally driven by real wage per hour. Growth in the number of LPNs per thousand (0.8\%) was offset by decrease in number of hours worked by about the same percentage $(-0.9 \%)$. This suggests that, as in the case of RNs, LPNs also worked less time in 2010 than in 2000 and by the same proportion.

At the provincial level, the pattern is pretty much similar: real wage per hour was either the only factor or the main factor driving LPN wage bill in each province, except in Quebec, where number of LPN per thousand was the main factor. Therefore, the provinces are paying more without getting significantly more LPN throughput, except for Quebec. Number of weekly hours worked dropped in each single province. Note that for Newfoundland-Labrador, both number of hours worked and number of LPN per thousand have dropped, suggesting that this province has been substituting RN for LPN. Numbers for PEI are not presented in this figure, owing to sample size issue. 


\section{Data Triangulation and Discussion}

Because of its large sample size and its link to administrative tax data, the 2011 NHS is a rich database capable of generating reliable estimates of average hourly wages, average number of hours worked and number of professionals. Still, it is worth assessing how it compares to other data sources. We have found that the count of regulated nurses in the NHS is close to the administrative CIHI (2011) NDB (with only $0.7 \%$ more in the NHS).

As for the hourly wage, the LFS represents another data source to which the NHS findings are compared. Average hourly wage for RNs in Canada in 2010 was estimated at $\$ 35.0$ in the NHS and $\$ 33.0$ in the LFS; a difference of 6.1\%. Note that NHS data include overtime, while LFS data do not. The CFNU (2011a) document offers also a basis for comparison of hourly rates of general-duty RNs and LPNs. However, it is not a direct comparison because only the range is available in this CFNU document and the rates are as of July 1, 2011. Having said that, it is still possible to use this source for comparison purposes: the minimum (maximum) can be interpreted as a lower (upper) bound. It is important to note that for both RNs and LPNs, the average hourly rate from the NHS generally fell within the CFNU range. Comparison of estimated total wage bill to figures from provincial health ministries was most exhaustive in Quebec, where figures for nurses in both the public and the private sectors were obtained. The discrepancy from the two sources was only $0.5 \%$.

Moreover, results based on the NHS and the SEPH (for the general worker) suggest that, during the past decade, RNs benefited from a "wage premium" estimated at 1.7 percentage points compared to the general worker. In the case of LPNs, the "wage premium" was estimated at 0.9 percentage points. So, the "wage premium" was more substantial for RNs than for LPNs. The fact that the pattern is the same and the results tend to converge independently of the data sources suggests that the estimates are robust. One limitation of the paper is that the 2000 income data are exclusively self-reported, while for 2010, they are based on a combination of self-reported and tax data. This could introduce some bias. However, comparison with LFS data (exclusively self-reported in 2000 and 2010) suggests that the bias is not substantial. With the LFS, real wage per hour for RNs is estimated to grow at an average annual rate of $2.2 \%$, which still suggests the existence of a wage premium. Another limitation of the study is that it does not address the issue of nurse workload or output. However, it is still a step that contributes to the existing literature. The results can be used later in conjunction with other clinical data sources to shed light on the issue of value for money in the nursing professional category. Indeed, future studies that address the issue of nurse compensation and workload or output are required. Then, decision-makers can rely on a more comprehensive setting for policy interventions.

\section{Conclusion}

At the Canada level, total wage bill for the nursing professional category in Canada was estimated at $\$ 20.1$ billion ( $\$ 17.3$ billion for $\mathrm{RNs}$ ), which suggests that it is as substantial as net physician remuneration. The average annual growth rate of this wage bill was $6.3 \%$ 
(6.6\% for RNs). This increase was mainly driven by real wage per hour $(3.0 \%$ above and beyond general inflation in the case of RNs). This finding is similar to physician cost driver studies, which found that unit price was the main driver of physician compensation in Canada for the 1998-2008 period (CIHI 2010) or in Quebec (Contandriopoulos and Perroux 2013) for the 2007-2011 period. It should be noted that real wage per hour in the general economy has grown only at an average annual rate of $1.3 \%$ between 2000 and 2010: which suggests the existence of a "health premium" of 1.7 percentage points for RNs. The "health premium" was lower for LPNs. While the number of nurses per thousand has contributed to the increase in the total wage bill, it was partially offset by the reduction in the numbers of hours worked per week. At the provincial level, the pattern is generally similar. Real wage per hour was the main factor driving RN wage bill in each province, except in PEI and $\mathrm{BC}$, where number of RN per thousand was the main factor. In the case of LPN, real wage per hour was either the only factor or the main factor driving wage bill in each province, except in Quebec, where number of LPN per thousand was the main factor. Pending a more comprehensive analysis that includes nursing workload and output, this finding suggests that in most provinces, governments are paying more without necessarily getting more nursing throughput.

\section{Disclaimer}

The views expressed in this paper are those of the authors and do not represent the opinions of their employing organizations.

Correspondence may be directed to: Ruolz Ariste, Joint Industrial Relations Program, Université du Québec en Outaouais (UQO) and Université Laval, 283 Boulevard Alexandre Taché, Gatineau, QC J8X 3X7; tel.: 613-863-8702; fax: 613-596-9807; e-mail: arir03@uqo.ca.

\section{Notes}

1. In this study, the term LPN is used to designate both licensed practical nurses and registered practical nurses.

2. This study does not include the nurses-aides, orderlies and patient service associates (D312), which are unregulated.

3. Based on the set of questions: During the year ending December 31, 2010, did this person receive any income from the following sources?

4. Personal e-mail communication with Statistics Canada.

5. Number of weekly hours was derived from the survey question: Last week (or during the week of Sunday, May 1, 2011 to Saturday, May 7, 2011), how many hours did this person spend working for pay or in self-employment?

6. Estimating the impact of population aging on nurse expenditures in Canada is difficult because data on nurse spending by age category do not exist.

7. The purpose of the comparison is to show the relative importance of the nurse wage bill in the public healthcare system. Medical services in Canada are privately delivered but also publicly funded. 
8. These numbers are obtained from a special CIHI data request where full-time is set as defined by the employer (generally, 35 hours of work and more per week). The same trend is observed when the NHS or the LFS is used - full-time defined as 30 hours of work and more per week. For example, Figure 8 in Laberge et Montmarquette (2009) uses the LFS to show an increased trend in the proportion of nurses working full-time between 1997 and 2007 in Quebec, Ontario and the rest of Canada.

9. CFNU (2011b) reports a weekly absenteeism rate of $8.1 \%$ for all nurses in the public sector in 2002 and 2010, with fluctuation of around 1 percentage point. Likewise, Laberge and Montmarquette (2009) report only a 2 percentage point increase in the absenteeism rate of nurses between 1997 and 2007. Depression was a significant determinant of absenteeism for both RNs and LPNs, namely, in the hospital setting (Basu and Rajbhandary 2010).

10. The figure for 2000 was obtained through a special CIHI data request.

11. For example, given that this professional category is highly unionized (Uppal 2011) with relatively difficult working conditions, employers and unions might come to mutual agreements during collective bargaining to improve nurse working conditions as a retention strategy and thus reduce the number of hours worked per week while still securing high increases in wage rate.

\section{References}

Ariste, R. forthcoming. "Fee-Schedule Increases in Canada: Implication for Service Volumes among Family and Specialist Physicians." Journal of Health and Human Services Administration.

Barer, M.L. and R.G. Evans. 1983."Prices, Proxies and Productivity: An Historical Analysis of Hospital and Medical Care in Canada." In W.E. Diewert and C. Montmarquette, eds., Price Level Measurement: Proceedings from a Conference Sponsored by Statistics Canada, Ottawa, ON.

Basu, K. and S. Rajbhandary.2010. “Working Conditions of Nurses and Absenteeism: Is There a Relationship? An Empirical Analysis Using National Survey of the Work and Health of Nurses." Health Policy 87: 152-59.

Baumann, A., M. CreaArsenio, D. Idriss-Wheeler, M. Hunsberger and J. Blythe. 2010."Health Human Resource Series Number 23. A MadeinLHIN Solution: Identifying Local Needs in 70\% Full-Time Nurse Employment." Central West LHIN 5 [Internet]. Hamilton, ON: Nursing Health Services Research Unit. Retrieved June 2010. $<$ http://www.nhsru.com>.

Buhr K. 2006. Three Essays on the Labour Market for Registered Nurses in Canada. PhD thesis. Carleton University, Available at ProQuest.

CFNU. 2011a. Overview of Key Nursing Contract Provisions. Retrieved from the Canadian Federation of Nurses Union on February 27, 2014. <http://www.nursesunions.ca/sites/default/files/2011.07.contract_comparison.e_0. pdf $>$.

CFNU. 2011b. Trends in Own Illness or Disability-Related Absenteeism and Overtime among Publicly-Employed Registered Nurses: Quick Facts. Prepared for the Canadian Federation of Nurses Unions by Informetrica Limited. Ottawa, ON.

Canadian Institute for Health Information (CIHI). 2006. Average Payment per Physician Report, Fee-for-Service Physicians in Canada, 2004-2005. Ottawa, ON: Canadian Institute for Health Information.

Canadian Institute for Health Information (CIHI). 2010. Healthcare Cost Drivers - the Facts. Ottawa, ON: Canadian Institute for Health Information. 
Canadian Institute for Health Information (CIHI). 2011. Regulated Nurses: Canadian Trends, 2006-2010. Ottawa, $\mathrm{ON}$ : Canadian Institute for Health Information.

Canadian Institute for Health Information (CIHI). 2013. National Health Expenditures Trends, 1975-2013. Ottawa, ON: Canadian Institute for Health Information.

Canadian Institute for Health Information (CIHI). 2014. Physicians in Canada, 2013: Summary Report. Ottawa, $\mathrm{ON}$ : Canadian Institute for Health Information.

Canadian Medical Association (CMA). 2010. National Physician Survey, 2010. Canadian Medical Association (Communication with the Workforce Research Unit). Statistics, reports and links on physician resources can be found at: <http://cma.ca/c3pr $>$.

Contandriopoulos, D. and M. Perroux. 2013. “Fee Increases and Target Income Hypothesis: Data from Quebec on Physicians' Compensation and Service Volumes." Healthcare Policy 9(2): 30-35. DOI:10.12927/hcpol.2013.23613. Hartwig, J. and J.E. Sturm. 2014. "Robust Determinants of Health Care Expenditure Growth." Applied Economics 46(36): 4455-74. DOI:10.1080/00036846.2014.964829.

Laberge M. and C. Montmarquette. 2009. Portraits des conditions de pratique et de la pénurie des effectifs infirmiers au Québec. CIRANO. Rapport de projet 2009 RP-01. Montreal, QC: CIRANO.

O'Brien-Pallas, L., G.T. Murphy, H. Laschinger, S. White, S. Wang and C. McCulloch. 2004. "Enquête auprès des infirmières et infirmiers des trois groupes professionnels au Canada." In Dans le contexte du projet : Construire lavenir : une stratégie intégrée pour les ressources humaines infirmières au Canada. Ottawa, ON: Société de létude sectorielle sur les soins infirmiers.

Statistics Canada. 2003. 2001 Census Handbook. Catalogue No. 92-379-XIE. Ottawa, ON: Author.

Statistics Canada. 2011. Income Reference Guide. National Household Survey. Analytical document. Catalogue no. 99-014-X2011006. Ottawa, ON: Author.

Statistics Canada. 2013. National Household Survey Dictionary, 2011. Catalogue no. 99-000-X2011001. Ottawa, ON: Author.

Uppal, S. 2011. “Unionization, 2011.” Perspectives on Labour and Income. Statistics Canada. Catalog No. 75-001X. Retrieved April 15, 2015. <http://www.statcan.gc.ca/pub/75-001-x/2011004/article/11579-eng.pdf>.

Vujicic, M. 2003. "Recent Trends in the Nursing Labour Market in Canada." PhD thesis, University of British Columbia, Department of Economics.

Zeytinoglu, I.U., M. Denton, S. Davies, A. Baumann, J. Blythe and L. Boos. 2006."Retaining Nurses in Their Employing Hospitals and in the Profession: Effects of Job Preference, Unpaid Overtime, Importance of Earnings and Stress." Health Policy 79(1): 57-72. 